\title{
Perspective
}

\section{Umuganda for improved health professions education in Rwanda: Past, present and future in the training of health professionals at the University of Rwanda}

\author{
Maaike Flinkenflogel ${ }^{1,2 *}$, Patrick Kyamanywa ${ }^{1}$, Brenda Asiimwe-Kateera ${ }^{1}$, Sanctus Musafiri ${ }^{1}$, \\ Pierre Claver Kayumba ${ }^{1}$, Magnifique Irakoze ${ }^{1}$, Phil Cotton ${ }^{1}$, Arthur Hibble ${ }^{3}$ \\ ${ }^{1}$ College of Medicine and Health Sciences, University of Rwanda, Rwanda \\ ${ }^{2}$ Inshuti Mu Buzima/ Partners In Health, Rwanda \\ ${ }^{3}$ Faculty of Health, Social Care and Education, Anglia Ruskin University, Cambridge, UK
}

\begin{abstract}
Background: Investing in health professions education is widely known to improve the overall health outcomes of a community, with collaboration as a strategy. Umuganda is a Rwandan concept of community collaboration. Objective: This article describes several recent milestones in collaborative development of health professional education at the College of Medicine and Health Sciences, University of Rwanda, towards more socially accountable education. Methodology: Literature review and personal experiences from the authors were used to describe recent milestones in the article. Results: In 2012 the 7-year Human Resources for Health (HRH) program was launched, in 2013 the new University of Rwanda created the College of Medicine and Health Sciences, in 2014 the undergraduate medical curriculum was revised, and incorporated interprofessionality and integrated social and community medicine training. Furthermore, innovative teaching methods were introduced to increase numbers of students.. In 2015 several international conferences were organised by the College of Medicine and Health Sciences. Conclusion: Innovation and collaboration go hand in hand in the development of health professions education. Recent milestones at the College of Medicine and Health Sciences, University of Rwanda, show the use and progress of 'umuganda' in the educational side of health care delivery.
\end{abstract}

Key words: Medical education, health professions education, Human Resources for Health, curriculum review, milestones, Rwanda

\section{Short history of medical education in Rwanda}

Nelson Mandela once said "Education is the most powerful tool which you can use to change the world" (Mandela, 2003). Investing in health professions education increases the quantity and develops the quality of the health workforce. Training health professions in understanding the needs of the community they work in creates a socially accountable health workforce which responds to the needs of the community, improving the health outcomes. In this article we describe several recent milestones with collaborative programs and activities in Rwanda's medical and other health professions education.

The former National University of Rwanda (NUR) opened in 1963 in Butare. From 1966 to 1989 there was a steady annual enrolment of 25 medical students in the undergraduate program and an annual output of 20 graduates. The university closed during the genocide in 1994, suffering from the massive loss of academic staff and medical students. In 1995 the university re-opened and since 1997 there has been an average intake of 100 medical students and an average output of 80 graduates per year. Before 1994, there was minimal postgraduate training in medicine and specialists were trained in $\mathrm{Eu}-$ rope, this approach stimulated brain drain (also known as human capital flight) immensely. After 1997 postgraduate and doctorate students were trained in a sandwich model, mainly with European universities to give them the opportunity to increase knowledge at the host university and put this knowledge into practice in Rwanda or collect research data in Rwanda to analyse this at the host institution in Europe. In 2005 the NUR started its own postgraduate training in medicine, surgery, obstetrics/ gynaecology, paediatrics and anaesthesiology, gradually increasing numbers and specialist disciplines to date. Subspecialist training is still largely outside of the country. In 2013 there were 684 doctors, 8,985 Nurses, 622 Midwives working in Rwanda, which gave a ratio of 1

*Corresponding author: Maaike.cotc@gmail.com 
doctor per 15,806 people, 1 nurse per 1203 people and 1 midwife per 17,381 people (Ministry of Health. Republic of Rwanda, 2013b), numbers of how many left the country over the years are not available.

\section{Umuganda in health professions education}

Umuganda is a Rwandan concept of community contribution to strengthen community cohesion, support community development and provide an opportunity for community members and leaders to come together for discussion and education. In the post-genocide era many innovations and initiatives to increase the numbers and improve the quality of health care professionals have been implemented within the umuganda-spirit of collaboration, cohesion and development. Some of these initiatives include the creation of East African Community Volunteers, collaboration with Ethiopian Universities, partnerships with European universities, partnerships with international Non-Governmental Organisations (NGOs) (Cancedda et al., 2014) and now the innovative Human Resources for Health (HRH) program (Binagwaho et al., 2013). During a 2008 conference 'Umuganda in Medical Education' on HRH, co-organised by the Ministry of Education and the then National University of Rwanda, it was highlighted that much had been accomplished since the genocide, but the limitation of resources (human, facilities, supplies and equipment) remained a substantive problem and the health workforce was in a crisis. Creative and collaborative thinking among health educators in an international and interdisciplinary way was needed to address the HRH challenges (Ministry of Health. Republic of Rwanda, 2008a; Ministry of Health, Republic of Rwanda, 2008b). Despite the low number of resources major changes have happened in medical education in Rwanda since 2008 although little has been described in the literature (Greysen et al., 2011).

\section{Recent milestones in Rwandan health profes- sions education}

The first milestone is a 7-year program to strengthen the training capacity of health professions education in Rwanda. In 2011 the Honourable Minister of Health, Dr. Agnes Binagwaho, the Faculty of Medicine at the former NUR and several international NGO's developed a bold program to address the critical issues in health care in Rwanda.. The 7-year Human Resources for Health (HRH) program was thus born. Embedded in the 20112016 Ministry of Health (MOH) Human Resources Strategic Plan (Ministry of Health. Republic of Rwanda, 2011a), the program is a partnership with a consortium of 19 top-ranking universities in the United States of America (USA) to strengthen the health care education infrastructure to develop a high quality and sustainable health care system (Binagwaho et al., 2013; Ministry of Health. Republic of Rwanda, 2011b; Sliney \& Uwimana, 2014). International specialists (mainly nursing and medicine, but also oral health and health management) share their skills and expertise with Rwandan counterparts to develop sustainable Masters level training of clinicians and educators. There have been challenges within the program, including USA universities having difficulties to recruit staff for longer periods, while CMHS prefers staff that stays long-term to develop a better connection with their counterparts and the setting they work in. Presently discussions between the MOH, CMHS and American universities are ongoing to get the agreements for the final years of this HRH program.

The second milestone is the merging of the Faculty of Medicine at the former NUR with the former Kigali Health Institute and three former schools of Nursing and Midwifery at to form an integrated and socially accountable College of Medicine and Health Sciences (CMHS) under the newly established public University of Rwanda in 2013. This new college has provided increased opportunities for collaboration in education, research and care delivery.

The third milestone is the 5-yearly undergraduate medical curriculum review. During the 2007-2009 curriculum review, the undergraduate medical training went from a course (linear teaching) to a modular (teaching blocks) system. In 2014 the newly formed School of Medicine and Pharmacy undertook a curriculum review to respond better to the needs of the Rwandan population and become more socially accountable. The curriculum was reduced from 6 to 5 years and the annual intake of medical students was doubled from 100 to 200 . The training is interdisciplinary with medical, pharmacy and dentistry students in the same classroom in the pre-clinical years. The new curriculum prepares medical, pharmacy and dentistry students to develop core competences of the 'desired Rwandan medical health care provider- a patient-centred and community-oriented health care provider with attitudes and skills of a communicator, collaborator, health advocate, manager, scholar and professional (University of Rwanda, School of Medicine, 2014), based on the 2005 CanMEDS framework (Frank, 2005). The curriculum has five important continuous themes of biomedical sciences, evidence-based medicine and medical informatics, ethics and professionalism, patient safety, and social medicine.

The most recent milestone is several recent international conferences focusing on health professions education that have been organised by CMHS. In January the School of 
Nursing and Midwifery organised the 'global innovations in nursing' conference that brought over 300 nurse and midwife educators, nurses and midwives and other related health professionals from Eastern Africa, USA and South Africa together to share experiences and discuss the contributions of nursing to improve care delivery. In June 2015 the University of Rwanda hosted the Third Eastern Africa Health Professions Educators' Association Conference on 'Innovations in health professional education'. Almost 200 people from 15 countries came together to share their success stories and challenges on themes including curriculum development, innovative teaching and learning methods, assessment of student assessment and research in health professions education. This was an important milestone for CMHS as it marked how collaboration in health professions education within the region can be strengthened to improve the quality of education, inter-university partnerships and collaborative research.

The CMHS is part of the East Africa Health Professions Educators Association (EAHPEA) which is a network of universities and health professions educators, started in 2013, that aims to share, support and inspire in the field of health professions education (Table 1). The overall objective of the EAHPEA is to raise the standards of educators and the educational experience of learners in the region.

\section{Table 1. The aims of the Eastern Africa Health Professions Educators Association (EAHPEA, 2015)}

- Share educational knowledge, skills, best-practices with each other

- Support each other's efforts to improve health professions education

- Inspire one another and our colleagues to achieve educational excellence in our work

- Identify educational needs and resources that could be of benefit to all

- Give educational inputs to faculties

- Identify and oversee facilitation of availability of core modules in educational topics

\section{Rwanda's way forward}

Rwanda is gaining its reputation internationally as a producer of a high quality sustainable health professions workforce with the HRH program increasing quantity and quality of medical specialists, nurses and midwives, oral health professionals and health managers (Ministry of Health. Republic of Rwanda, 2015). The Rwandan health system is continuing to train its health professions workforce to strengthen the primary health care platform (Binagwaho et al., 2014), with community based health insurance (Ministry of health, Republic of Rwanda, 2010), community health workers (Condo et al., 2014), increasing the accessibility by building more health posts and scaling-up nurses in the health centres (Ministry of Health, Republic of Rwanda, 2013a). In the undergraduate medical curriculum an integrated social and community medicine training is preparing the next generation of medical doctors with a primary health care mind-set to understand the needs of the Rwandan community.

The revised undergraduate medical training is in its first year of implementation and the increased numbers of medical students created challenges like high student-faculty ratio and classroom space. The School has implemented several innovations such as Team Based Learning (Michaelsen, Parmelee, McMahon, \& Levine, 2008), the flipped classroom method (McLaughlin et al., 2014) and introduction of an online learning platform (College of Medicine and Health Sciences, University of Rwanda, 2015) to enhance teaching and learning. The university is putting in considerable effort to overcome the challenge of unreliable internet to give students and teachers continuous access to the online platform. With the growing numbers of students, future plans include more student-led learning with reduced contact time for lectures, more formal assessments and increased practical and experiential learning in laboratories and at the bedside. Interprofessional education and research is increasing and benchmarking is taking place in the different medical specialities.

\section{Conclusion}

All innovations in the development of health professions education in Rwanda have one overarching objective: to use the umuganda-spirit in collaboration and strengthening of forces to improve health professions education and the overall health standards for the Rwandan community.

\section{Conflict of interest}

Several of the authors were in the organising committee for the 2015 East Africa Health Professions Educators Association which was discussed in this article.

\section{References}

Binagwaho, A., Farmer, P. E., Nsanzimana, S., Karema, C., Gasana, M., de Dieu Ngirabega, J., Drobac, P. C. (2014). Rwanda 20 years on: investing in life. The Lancet, 384(9940), 37114). Rwanda 20 years on: investing 6736(14)60574-2 
Binagwaho, A., Kyamanywa, P., Farmer, P. E., Nuthulaganti, T., Umubyeyi, B., Nyemazi, J. P., others. (2013). The human resources for health program in Rwandanda health program iNew England Journal of Medicine, 369(21), 2054d Jour

Cancedda, C., Farmer, P. E., Kyamanywa, P., Riviello, R., Rhatigan, J., Wagner, C. M., Binagwaho, A. (2014). Enhancing Formal Educational and In-Service Training Programs in Rural Rwanda: A Partnership Among the Public Sector, a Nongovernmental Organization, and Academia. Academic Medicine, 89(8), 1117Mediciner, a Nongovernmental Organization, and Aca

College of Medicine and Health Sciences. University of Rwanda. (2015). UR CMHS Online course delivery platform. Retrieved from http://cmhs.tulanerw.org/md/

Condo, J., Mugeni, C., Naughton, B., Hall, K., Tuazon, M. A., Omwega, A., . Binagwaho, A. (2014). Rwanda). RwandaandaandaRwanda . Binagwaho, A. (2014). Rwanda. RwandaRwandaRwanda14). Rwandaatform. Retrieved from12(71). Retrieved from http://www.human-resources-health.com/ content/12/1/71

EAHPEA. (2015). Eastern Africa Health Professions Educators Association. Retrieved from https://sites.google.com/ site/eamededucators/eahpea-front-page

Frank, J. (2005). The CanMEDS 2005 physician competency framework 2005. Better standards. Better Physicians. Better Care. Royal College of Physicians and Surgeons of Canada.

Greysen, S. R., Dovlo, D., Olapade-Olaopa, E. O., Jacobs, M., Sewankambo, N., \& Mullan, F. (2011). Medical education in sub-Saharan Africa: a literature review: Medical education in sub-Saharan Africa. Medical Education, 45(10), 973ducationcal education in sub-Saharan Africa: a litera

Mandela, N. (2003). Former President Republic of South Africa, 1993 Nobel Peace Prize laureate. Retrieved from http:/ / www.un.org/en/globalissues/briefingpapers/efa/quotes. shtml

McLaughlin, J. E., Roth, M. T., Glatt, D. M., Gharkholonarehe, N., Davidson, C. A., Griffin, L. M., . Mumper, R. J. (2014). The Flipped Classroom: A Course Redesign to Foster Learning and Engagement in a Health Professions School. Academic Medicine, 89(2), 236 Mediciner Learning and Engagement in a Health $\mathrm{Pr}$

Michaelsen, L., Parmelee, D., McMahon, K., \& Levine, R. (2008). Team-based learning for health professions education: A guide to using small groups for improving learning. Sterling Virginia: Stylus Publishing.
Ministry of health. Republic of Rwanda. (2010). Rwanda national health insurance policy. Retrieved from www.hst. org.za/sites/default/files/2bcce61d2d1b8d972af41ab0e2c8a4ab.pdf

Ministry of Health. Republic of Rwanda. (2008a). Conference on coordination of medical education in Rwanda. "UMUGANDA for Medical Education in Rwanda." Kigali, Rwanda.

Ministry of Health. Republic of Rwanda. (2008b). Conference: Coordination of Medical Education in Rwanda. Final summary and themes. Kigali, Rwanda.

Ministry of Health. Republic of Rwanda. (2011a). Human Resources for Health strategic plan 2011-2016. Retrieved from http://www.moh.gov.rw/fileadmin/templates/policies/HRH__STRATEGIC_PLAN_2011_-_2016_AP_ PROVED.pdf

Ministry of Health. Republic of Rwanda. (2011b). Rwanda Human Resources for Health Program, 2011-2019.

Ministry of Health. Republic of Rwanda. (2013a). National Community Health Policy of Rwanda 2013-2018. Retrieved from http://www.nationalplanningcycles.org/sites/default/files/country_docs/Rwanda/chd-strategic_plan.pdf

Ministry of Health. Republic of Rwanda. (2013b). Rwanda Annual Health Statistics Booklet 2013. Rwanda. Retrieved from http://www.moh.gov.rw/fileadmin/templates/policies/ Rwanda_Annual_Health_Statistics_Booklet_2013_signed. pdf

Ministry of Health. Republic of Rwanda. (2015, April). HRH consortium Rwanda. Retrieved from www.hrhconsortium. moh.gov.rw/

Sliney, A., \& Uwimana, C. (2014). Human Resources for Health Program - Rwandan Health Care System. In Global Health Nursing: Building and Sustaining Partnerships (pp. 209alth Nursing: Building and Sustaini

University of Rwanda. School of Medicine. (2014). Undergraduate medical training framework. Roles of the "The desired Rwandan Medical Doctor". Curriculum review 2014. 